\title{
Good Practice
}

\section{What is a good GP?}

\author{
CHRISTIAN HEATH
}

The daily practice of medicine-the process of diagnosis and treatment-is thoroughly bound up in the ways in which the doctor and patient communicate. In this essay I wish to suggest that being a "good" general practitioner is dependent upon the form of the doctor's communication and that the non-verbal behaviour of the doctor is central to the success or failure of the consultation.

Communication is important in the consultation not just because it is pertinent to the doctor-patient relationship or linked to ideas about patient centred medicine. More fundamentally, doctors, like other professionals, rely on the information provided by patients to make decisions concerning the nature of the illness and the appropriate treatment. Patients provide this information largely in their answers to questions put by the practitioner; the patient is continually in second position-that is, his or her actions are responsive to the doctor's. Thus the ways in which doctors behave both verbally and non-verbally influence what patients say and how they say it. Furthermore, there is evidence that whether or not patients actually follow the doctor's advice on management and treatment depends on the information that the doctor provides and the way it is communicated to the patient. In fact the causes of a variety of problems in the delivery of health care, ranging from mistaken diagnosis to compliance with treatment, may be found in the communication that occurs between the doctor and the patient. Had this been realised sooner, considerable research funding might have been saved, or at least redirected. We still need to know more about the workings of the consultation.

The importance of the verbal behaviour of the doctor is obvious. The way in which a question is framed determines what information is received in reply. But the importance of non-verbal communication is less apparent, and a lot of popular books have appeared, which, though entertaining, trivialise its use and effects. A careful examination of the non-verbal behaviour of human beings, however, shows it to be systematic and related to the ways in which people speak. Video recording has allowed the behavioural scientist to record people's behaviour using action replay and slow motion.

Faculty of Human Studies, University of Surrey, Guildford GU2 5XH CHRISTIAN HEATH, PHD, lecturer
In fact, video recording has revolutionised the behavioural sciences, providing a cheap and reliable means of capturing the visual and vocal behaviour of, for instance, doctors and patients in the consultation. Its impact may be similar to that of the microscope in biology.

\section{Coordinated behaviour}

A recent study of the visual and vocal behaviour in the medical consultation entailed the detailed analysis of more than 1000 hours of daily consultations in general practice which were recorded throughout the United Kingdom. It became apparent that, far from being idiosyncratic, the body movement of doctor and patient in the consultation is highly organised and systematic. The participants continually coordinated their non-verbal behaviour with each other and the talk in which they were engaged. This mutual coordination of body movement ranged from the slightest eye movement to major shifts in orientation, such as rearranging a sitting position. Using high quality, slow motion facilities, we noticed that at different stages during the consultation the doctor and patient developed mutual rhythms in the flow of their body movements, temporarily setting a particular pace and synchrony. It also emerged that trouble spots in a consultation, ranging from hesitations in speech to full blown disagreements, were embedded in phases of asynchrony in non-verbal and verbal communication.

\section{GIVING INFORMATION TO THE-DOCTOR}

Transcribing the communication in the consultation shows that there are stretches of talk where the patient has great difficulty speaking. The patient may withhold a reply, pause, utter "ums" and "ers," lengthen the sounds of the words, or begin a new reply before finishing the previous one, and sometimes stop speaking altogether. Such difficulties in delivering information to the doctor are independent of variables such as social class, age, or sex, nor are they related to the language competence of the speaker. These troubled stretches of talk are interspersed with clear, unperturbed speech by the patient. The source of the difficulties lies in the visual communication of the doctor. If the doctor fails to look at the patient as the patient begins to speak, or turns away during the reply, the patient has difficulty speaking. The problems are accentuated because of the ways in which some practitioners use the medical record cards or computer systems during the consultation. Through non-verbal behaviour the doctor unwittingly causes difficulties for the patient and thereby undermines the information received 
from the patient, who delays, curtails, and sometimes abandons replies. These problems are echoed in asynchrony in the non-verbal communication of the participants.

Some practitioners avoid creating these difficulties by, for example, glancing at the medical records or computer screen before the patient enters the office. If they need to use the records during the consultation they wait until the patient has finished speaking on a subject or seek permission before turning away. Thus they keep their attention on the patient, who is delivering information, and thereby avoid generating speech difficulties, missing important points, and, of course, undermining the relationship between doctor and patient.

\section{Embarrassment during the physical examination}

During the physical examination some practitioners inadvertently cause embarrassment for both them and their patients, which may make the patient tense and uncooperative. Sometimes the examination is even curtailed or abandoned. Such embarrassment may arise when doctor and patient are preparing for the examination. For instance, the orientation of the doctor's body and pattern of gaze may cause mutual embarrassment. An easy going doctor who engages in small talk and insists on mutual involvement before and during the examination (to put the patient "at ease") causes more problems than he or she avoids.

The physical examination is carried out more smoothly and with fewer difficulties when conducted formally, both visually and vocally, than if informality is attempted. When the practitioner asked the patient's permission to conduct the examination and then turned away and became occupied elsewhere while the patient prepared for the examination there were few difficulties. The practitioners who ignored a patient's preparation for the examination therefore allowed patients to distance themselves from the examination and retained their cooperation. Thus relatively small differences in the non-verbal behaviour of practitioners can have an appreciable influence on the care with which the examination is conducted and its influence on assessment and diagnosis.

\section{Doctor's behaviour is crucial}

Analysis of the medical consultation shows that non-verbal as well as verbal communication is an important part of the process through which practitioners diagnose illness and recommend treatment. The coherence and the type of information the doctor is able to gather, the usefulness of the examination, the persuasiveness of the advice, and other aspects of practical medical work are greatly affected by the non-verbal behaviour of the practitioner. The success or failure of the consultation and the relationship between the patient and the doctor in both the short and the long term are inseparable from the nature of the communication. "Good" general practice depends on the non-verbal as well as verbal behaviour of the doctor. Research and training in communication in the consultation will help to maintain and improve quality in the delivery of primary health care.

This article is based on research conducted as part of a project funded by the Economic and Social Research Council (HR/5148, HR/8143) concerned with doctor-patient communication. A book based on the research, Body Movement and Speech in Medical Interaction, has recently been published by Cambridge University Press with Editions de la Maison des Sciences de l'Homme, Paris.

\title{
Practice Research
}

\section{Are the recommendations being met in the general practice year of vocational training? Trainees' views in the West Midlands region}

\author{
ALLAN MICHAEL CYNA, FRANCIS RICHARD PRZYSLO
}

\begin{abstract}
Vocational trainees in the West Midlands who were in their general practice year were sent a postal questionnaire to find out whether there were important differences between the criteria for training of the 1986 West Midland postgraduate education committee (based on national recommendations) and the perceptions of the trainees of their current trainers and practices. The response rate was $86.2 \%$ ( 75 out of 87 ). Sixty four per cent ( 48 ) of trainees reported that they received on average less than the recommended minimum of three hours of teaching time a week. They felt that experience was inadequate in paediatric surveillance $(62 \cdot 7 \%)$ and preventive medical care (37.3\%). Most trainers gave topic teaching $(90.7 \%)$, and few used role play (5\%). Most of the trainees $(52 \%)$ had not signed a contract, a third did not get help with recommended allowances, and $37 \%$ thought that their progress had not been reviewed.
\end{abstract}

Several trainees commented on the excellence of their training

Stone, Staffs

ALLAN MICHAEL CYNA, MB, CHB, trainee general practitioner FRANCIS RICHARD PRZYSLO, BMEDSCI, BM, trainee general practitioner

Correspondence to: Dr F R Przyslo, Harley Street Health Centre, Harley Street, Hanley, Stoke on Trent, Staffs ST1 3RX. practices, and most of the practices appeared to be keeping to the spirit of the recommendations. There are, however, discrepancies between what some trainees feel they receive and what is recommended.

\section{Introduction}

The present system of selecting general practice trainers and practices dates from October 1973 when general practice training came under the academic control of the universities. At the beginning of 1975 the Joint Committee for Postgraduate Training in General Practice became autonomous, representing the two main bodies of general practice, the Royal College of General Practitioners and the General Medical Services Committee.' The educational aims for vocational training were set out by the second European conference on the teaching of general practice. ${ }^{2}$ In 1976 these aims were adopted by the Joint Committee as the basis for standards to be met by general practitioner trainers and their practices. ${ }^{3}$ These standards are applied to the general practice year that is undertaken by doctors as part of their vocational training, which has been a compulsory requirement since 1981 for every doctor who wishes to become a principal in general practice. ${ }^{4}$ In 1980 the fourth national trainee conference sought the views of trainees concerning vocational training and identified problems and unmet needs of trainees. 